HUMANIKA Vol. 23 No. 2 (2016) ISSN 1412-9418

\title{
DESKRIPSI PERBEDAAN FONOLOGI BAHASA -BAHASA DI WILAYAH BARAT PROVINSI JAWA TENGAH
}

\author{
Oleh: \\ Siti Junawaroh \\ Fakultas Ilmu Budaya Universitas Jenderal Soedirman \\ sjunawaroh.1981@yahoo.com
}

\begin{abstract}
Study description phonology differences in the western region of Central Java Province include Javanese and Sundanese used side by side in the region of Brebes and Cilacap . In the study dialectology, phonology deskription serves to illustrate the differences and variations correspondence contained in the observation point. For the western region of Central Java province contained the correspondence was perfect and less than perfect correspondence . Perfect correspondence in the form of correspondence sound $b-w$. Correspondence less than perfect form of correspondence $h-\varnothing$, In addition, there are also variations consonants $d-n, h-$ k, h-ng , h-s , g-k , w-c , K- $\varnothing$ and vocal variety, i-e , u-o , u-a ,VV - V , V - Ø.
\end{abstract}

\section{PENDAHULUAN}

Wilayah barat Provinsi Jawa tengah meliputi Kabupaten Brebes dan Kabupaten Cilacap. Di kedua kabupaten ini terdapat dua bahasa daerah yang dipakai secara luas oleh masyarakat, yakni bahasa Jawa dan bahasa Sunda. Bahasa Jawa terdapat di sebagian besar wilayah di Kabupaten Brebes dan Kabupaten Cilacap. Beberapa wilayah di dua kabupaten ini berpenutur bahasa Sunda.

Deskripsi perbedaan fonologi merupakan salah satu tahap dalam penelitian dialektologi. Dalam kajian dialektologi, deskripsi perbedaan unsurunsur kebahasaan mencakup fonologi, morfologi, sintaksis, leksikon,dan semantik. Perbedaan fonologi menyangkut perbedaan fonologis yang dapat berupa korespondensi bunyi dan variasi bunyi. Korespondensi bunyi meliputi korespondensi sangat sempurna, korespondensi sempurna, dan perbedaan yang berupa korespondensi kurang sempurna. Variasi bunyi meliputi variasi konsonan dan variasi vokal.
Deskripsi perbedaan fonologi kedua bahasa ini relevan dilakukan, karena walaupun dua bahasa yang berbeda, tetapi masyarakat di dua kabupaten ini cenderung paham dan kadang saling berganti kosakata yang dipakai. Hal ini menunjukkan kekerabatan bahasa yang dipakai di wilayah ini (Junawaroh dan Hidayat, 2013: 102 ).

\section{KERANGKA TEORI}

Perbedaan yang mendasar antara bentuk-bentuk yang dikategorikan sebagai bentuk yang berbeda secara fonologis dengan yang berbeda secara leksikal terletak pada dapat/tidaknya bentuk-bentuk yang berbeda itu dihubungkan pada sebuah bentuk purba yang sama. Apabila bentukbentuk yang berbeda itu dapat dihubungkan pada sebuah bentuk bahasa purba yang sama, bentuk-bentuk yang berbeda itu dikategorikan berbeda secara fonologis, sebaliknya jika bentuk-bentuk yang berbeda itu tidak dapat dihubungan pada sebuah bentuk asal yang sama, perbedaan itu terjadi pada level leksikal. Sebagai contoh, pasangan bentuk yang 
berbeda dalam BS: don $(\mathrm{DJ})=$ din $(\mathrm{DT})=$ dain $\quad(\mathrm{DT} n)=d \operatorname{In} \quad(\mathrm{DSB}) \quad$ 'daun' merupakan pasangan yang perbedaannya dapat dikategorikan sebagai perbedaan pada level fonologis karena dapat dilacak pada asal yang sama, yaitu diturunkan dari bahasa purba yang sama, yaitu PAN/PBSS *daun 'daun'; sedangkan pasangan bentuk yang berbeda dalam bahasa yang sama: ayam (DJ, DT. DSB) manuk (DTn) 'ayam' merupakan dua bentuk yang dikategorikan sebagai bentuk yang pada level leksikon karena masing-masing berasal dari bentuk purba yang berbeda.

Dapat ditambahkan bahwa perbedaan pada level fonologi ini mencakup perbedaan yang bersifat teratur atau korespondensi dan perubahan yang bersifat sporadis (tidak teratur) atau yang disebut variasi. Termasuk ke dalam perbedaan yang bersifat teratur ini adalah apa yang sebut sebagai korespondensi sangat sempurna, sempurna, dan kurang sempurna.

Perbedaan ini disebut korespondensi sangat sempurna apabila perbedaan-perbedaan yang disebabkan oleh perubahan bunyi itu terjadi pada semua data yang disyarati oleh kaidah perubahan serta sebaran geografisnya sama, sedangkan perbedaan yang berupa korespondensi sempurna juga terjadi pada semua data yang disyarati oleh kaidah perubahan, tetapi sebaran geografis antarcontoh yang satu dengan contoh yang lainnya tidak sama. Adapun perbedaan disebut korespondensi kurang sempurna jika perubahan bunyi itu terjadi pada 2-5 buah contoh dengan sebaran geografis yang sama dan perbedaan disebut variasi jika kaidah perubahan bunyi itu hanya terjadi pada sebuah atau dua buah contoh dengan sebaran geografis yang berbeda (Mahsun, 1995:51).

\section{METODE}

\subsection{Metode pengumpulan data}

Data yang diambil dari informan diperoleh dengan menggunakan metode cakap (Sudaryanto, 1988:2). Metode cakap dilakukan dengan wawancara langsung ke lapangan. Teknik yang digunakan adalah teknik cakapan terarah. Wawancara dilakukan dengan menggunakan bantuan instumen penelitian berupa daftar kosakata budaya dasar (Keraf, 1996:142). Teknik lanjutan yang digunakan adalah teknik catat dan rekam. Selama proses wawancara, dilakukan perekaman pembicaraan dengan menggunakan alat perekam dan pencatatan data dengan menggunakan kartu data.

Sumber data yang dipakai dalam penelitian ini adalah informan. Penentuan informan dipertimbangkan dengan kriteria:

a. Laki-laki atau Perempuan;

b. Sehat jasmani dan rohani;

c. Penduduk asli daerah yang diteliti;

d. Menguasai bahasa yang diteliti;

e. Pendidikan maksimal SLTP;

f. Jarang atau bahkan tidak pernah keluar dari wilayah tersebut;

g. Usia dewasa (25-60 tahun);

h. Masih memiliki alat ucap yang normal.

Jumlah informan di setiap sampel penelitian yaitu tiga orang.

Berikut penomoran wilayah penelitian.

\begin{tabular}{|c|l|}
\hline 1 & Losari \\
\hline 2 & Luwungbata \\
\hline 3 & Negla \\
\hline 4 & Sarireja \\
\hline 5 & Cikandang \\
\hline 6 & Pende \\
\hline 7 & Ketanggungan \\
\hline 8 & Buara \\
\hline 9 & Larangan \\
\hline 10 & Kamal \\
\hline 11 & Pangebatan \\
\hline 12 & Jipang \\
\hline 13 & Madusari \\
\hline 14 & Wanareja \\
\hline 15 & Adimulya \\
\hline 16 & Matenggeng \\
\hline 17 & Panulisan Timur \\
\hline 18 & Sindangsari \\
\hline 19 & Cilopadang \\
\hline 20 & Sidamulya \\
\hline
\end{tabular}


HUMANIKA Vol. 23 No. 2 (2016) ISSN 1412-9418

Deskripsi Perbedaan Fonologi Bahasa -Bahasa Di Wilayah Barat Provinsi Jawa Tengah

Siti Junawaroh

\begin{tabular}{|l|l|}
\hline 21 & Kunci \\
\hline 22 & Karangpucung \\
\hline 23 & Surusunda \\
\hline 24 & Banjarharjo \\
\hline 25 & Cikakak \\
\hline 26 & Bantarmangu \\
\hline 27 & Cimanggu \\
\hline
\end{tabular}

\subsection{Metode Analisis Data}

Sehubungan dengan itu, analisis data dilakukan dengan metode yang lazim digunakan dalam penelitian dialektologi. Untuk itu, berisi peta verbal yang menggambarkan perbedaan fonologi. Dari sudut pandang perbedaan fonologis, pilihlah alternatif peta yang kaidahnya

sama dengan kaidah dalam alternatif pemetaan pada glos lainya. Pengertian sama di sini tidak hanya sama kaidahnya, tetapi sama atau relatif sama daerah yang disatukan oleh kaidah tersebut. Hal itu bermanfaat untuk mengidentifikasi peta yang berupa korespondensi dan variasi.

\section{PEMBAHASAN}

Deskripsi perbedaan fonologi bahasa-bahasa di wilayah barat Provinsi Jawa Tengah dapat dikelompokkan dalam empat tipe perbedaan fonologi, yakni korespondensi sangat sempurna, korespondensi sempurna, korespondensi kurang sempurna, dan variasi.

\subsection{Korespondensi sangat sempurna}

Korespondensi sangat sempurna terjadi apabila perbedaan-perbedaan yang disebabkan oleh perubahan bunyi itu terjadi pada semua data yang disyarati oleh kaidah perubahan serta sebaran geografisnya sama.Data berikut menunjukkan korespondensi bunyi yang teratur yang terjadi pada titik pengamatan yang sama. Hal ini dapat dipahami bahwa antara titik-titik pengamatan tersebut merupakan dua bahasa yang berbeda, yakni titik $3,4,6,8,10,12,13,16,17,23,25$, 27 daerah berbahasa Sunda dan titik 1, 2,5,7,9,11,14,15, 18, 19, 20, 21, 22, 24, 26 daerah berbahasa Jawa, atau sebagian masyarakat berbahasa Jawa dan sebagian lagi berbahasa Sunda.

Korespondensi yang terjadi yakni fonem b (bahasa Sunda) berkorespondensi dengan fonem $\mathrm{w}$ dalam bahasa Jawa pada fonem pertama suatu kata. Berikut bentuk kosakata yang berkorespondensi sangat sempurna dan wilayah pemakaiannya

\begin{tabular}{|c|c|c|}
\hline $\begin{array}{l}\text { Bentuk } \\
\text { realisasi }\end{array}$ & Kosakata & Daerah pengamatan \\
\hline \multirow[t]{8}{*}{ b-w/\#- } & $\begin{array}{l}\text { bitis } \\
\text { wentis }\end{array}$ & 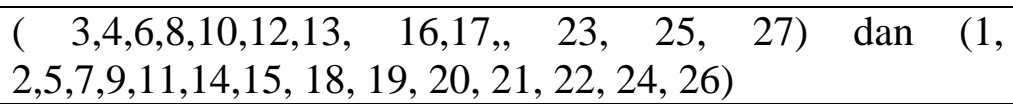 \\
\hline & $\begin{array}{l}\text { beteng } \\
\text { weteng }\end{array}$ & 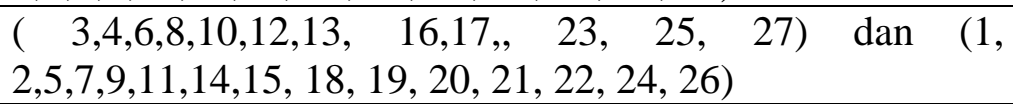 \\
\hline & $\begin{array}{l}\text { bujal } \\
\text { wudel }\end{array}$ & 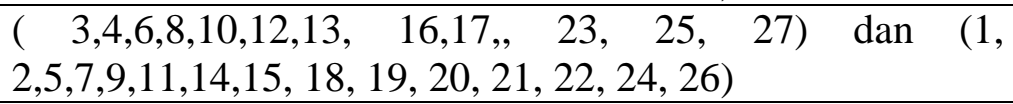 \\
\hline & $\begin{array}{l}\text { binih } \\
\text { winih }\end{array}$ & 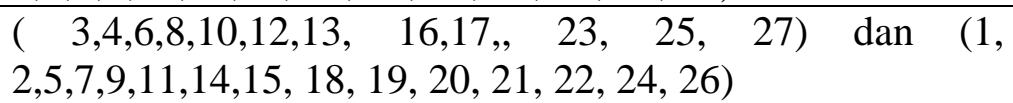 \\
\hline & $\begin{array}{l}\text { bulan } \\
\text { wulan }\end{array}$ & 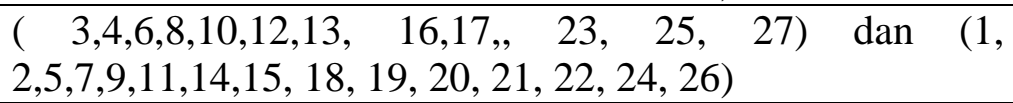 \\
\hline & $\begin{array}{l}\text { besi } \\
\text { wesi }\end{array}$ & $\begin{array}{l}3,4,6,8,10,12,13, \quad 16,17,, 23,25, \quad 27) \\
2,5,7,9,11,14,15,18,19,20,21,22,24,26)\end{array}$ \\
\hline & $\begin{array}{l}\text { bengi } \\
\text { wengi }\end{array}$ & 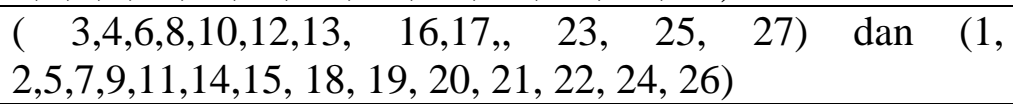 \\
\hline & $\begin{array}{l}\text { batuk } \\
\text { watuk }\end{array}$ & 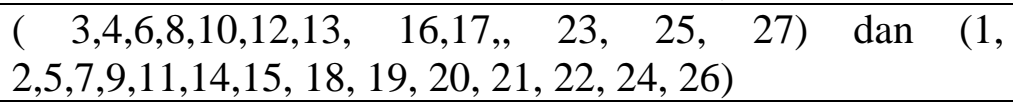 \\
\hline
\end{tabular}


HUMANIKA Vol. 23 No. 2 (2016) ISSN 1412-9418

Deskripsi Perbedaan Fonologi Bahasa -Bahasa Di Wilayah Barat Provinsi Jawa Tengah Siti Junawaroh

4.2. Korespondensi kurang sempurna

Korespondensi kurang sempurna terjadi jika perubahan bunyi itu terjadi pada 2-5 buah contoh dengan sebaran geografis yang sama

\begin{tabular}{|c|c|c|c|}
\hline No & $\begin{array}{l}\text { Bentuk } \\
\text { realisasi }\end{array}$ & kosakata & Daerah pengamatan \\
\hline \multirow[t]{4}{*}{$\mathrm{a}$} & h- Ø/\#- & $\begin{array}{l}\text { halis } \\
\text { alis }\end{array}$ & $\begin{array}{l}(3,4,6,8,10,12,13,16,17,23,25,27) \text { dan }(1, \\
2,5,7,9,11,14,15,18,19,20,21,22,24,26)\end{array}$ \\
\hline & & $\begin{array}{l}\text { huntu } \\
\text { untu }\end{array}$ & $\begin{array}{l}(3,4,6,8,10,12,13,16,17,23,25,27) \text { dan }(1, \\
2,5,7,9,11,14,15,18,19,20,21,22,24,26)\end{array}$ \\
\hline & & $\begin{array}{l}\text { hasem } \\
\text { asem }\end{array}$ & $\begin{array}{l}(3,4,6,8,10,12,13,16,17,23,25,27) \text { dan }(1, \\
2,5,7,9,11,14,15,18,19,20,21,22,24,26)\end{array}$ \\
\hline & & $\begin{array}{l}\text { hate } \\
\text { ati }\end{array}$ & $\begin{array}{l}(3,4,6,8,10,12,13,16,17,23,25,27) \text { dan }(1, \\
2,5,7,9,11,14,15,18,19,20,21,22,24,26)\end{array}$ \\
\hline \multirow[t]{2}{*}{$\mathrm{b}$} & $\begin{array}{l}\text { h- } \varnothing / \# \\
(\mathrm{~V})-\end{array}$ & $\begin{array}{l}\text { lahir } \\
\text { lair }\end{array}$ & $\begin{array}{l}(3,4,6,8,10,12,13,16,17,23,25,27) \text { dan }(1, \\
2,5,7,9,11,14,15,18,19,20,21,22,24,26)\end{array}$ \\
\hline & & $\begin{array}{l}\text { parahu } \\
\text { prau }\end{array}$ & $\begin{array}{l}(3,4,6,8,10,12,13,16,17,23,25,27) \text { dan }(1, \\
2,5,7,9,11,14,15,18,19,20,21,22,24,26)\end{array}$ \\
\hline \multirow[t]{4}{*}{$\mathrm{c}$} & $\begin{array}{l}\mathrm{V}- \\
\varnothing / \#(\mathrm{~K})-\end{array}$ & $\begin{array}{l}\text { salamet } \\
\text { slamet }\end{array}$ & $\begin{array}{l}(3,4,6,8,10,12,13,16,17,23,25,27) \text { dan }(1, \\
2,5,7,9,11,14,15,18,19,20,21,22,24,26)\end{array}$ \\
\hline & & $\begin{array}{l}\text { wuluku } \\
\text { wluku }\end{array}$ & $\begin{array}{l}(3,4,6,8,10,12,13,16,17,23,25,27) \text { dan }(1, \\
2,5,7,9,11,14,15,18,19,20,21,22,24,26)\end{array}$ \\
\hline & & $\begin{array}{l}\text { kurupuk } \\
\text { krupuk }\end{array}$ & $\begin{array}{l}(3,4,6,8,10,12,13,16,17,23,25,27) \text { dan }(1, \\
2,5,7,9,11,14,15,18,19,20,21,22,24,26)\end{array}$ \\
\hline & & $\begin{array}{l}\text { pariksa } \\
\text { priksa }\end{array}$ & $\begin{array}{l}(3,4,6,8,10,12,13,16,17,23,25,27) \text { dan }(1, \\
2,5,7,9,11,14,15,18,19,20,21,22,24,26)\end{array}$ \\
\hline \multirow[t]{4}{*}{ d } & $d-t /-\#$ & $\begin{array}{l}\text { layad } \\
\text { layat }\end{array}$ & $\begin{array}{l}(3,4,6,8,10,12,13,16,17,, 23,25,27) \text { dan }(1, \\
2,5,7,9,11,14,15,18,19,20,21,22,24,26)\end{array}$ \\
\hline & & $\begin{array}{l}\text { parud } \\
\text { parut }\end{array}$ & $\begin{array}{l}(3,4,6,8,10,12,13,16,17,23,25,27) \text { dan }(1, \\
2,5,7,9,11,14,15,18,19,20,21,22,24,26)\end{array}$ \\
\hline & & $\begin{array}{l}\text { mede } \\
\text { mete }\end{array}$ & $\begin{array}{l}(3,4,6,8,10,12,13,16,17,23,25,27) \text { dan }(1, \\
2,5,7,9,11,14,15,18,19,20,21,22,24,26)\end{array}$ \\
\hline & & $\begin{array}{l}\text { gendeng } \\
\text { genteng }\end{array}$ & $\begin{array}{l}(3,4,6,8,10,12,13,16,17,23,25,27) \text { dan }(1, \\
2,5,7,9,11,14,15,18,19,20,21,22,24,26)\end{array}$ \\
\hline \multirow[t]{3}{*}{$\mathrm{e}$} & a-e/\#(K)- & $\begin{array}{l}\text { padaringan } \\
\text { pedaringan }\end{array}$ & $\begin{array}{l}(3,4,6,8,10,12,13,16,17,23,25,27) \text { dan }(1, \\
2,5,7,9,11,14,15,18,19,20,21,22,24,26)\end{array}$ \\
\hline & & $\begin{array}{l}\text { gandong } \\
\text { gendong }\end{array}$ & $\begin{array}{l}(3,4,6,8,10,12,13,16,17,23,25,27) \text { dan }(1, \\
2,5,7,9,11,14,15,18,19,20,21,22,24,26)\end{array}$ \\
\hline & & $\begin{array}{l}\text { saturuy } \\
\text { setundun }\end{array}$ & $\begin{array}{l}(3,4,6,8,10,12,13,16,17,223,25,27) \text { dan }(1, \\
2,5,7,9,11,14,15,18,19,20,21,22,24,26)\end{array}$ \\
\hline \multirow[t]{4}{*}{$f$} & i-e/\#- & $\begin{array}{l}\text { isuk } \\
\text { esuk }\end{array}$ & $\begin{array}{l}(3,4,6,8,10,12,13,16,17,23,25,27) \text { dan }(1, \\
2,5,7,9,11,14,15,18,19,20,21,22,24,26)\end{array}$ \\
\hline & & $\begin{array}{l}\text { milu } \\
\text { melu }\end{array}$ & $\begin{array}{l}(3,4,6,8,10,12,13,16,17,23,25,27) \text { dan }(1, \\
2,5,7,9,11,14,15,18,19,20,21,22,24,26)\end{array}$ \\
\hline & & $\begin{array}{l}\text { ngitung } \\
\text { ngetung }\end{array}$ & $\begin{array}{l}(3,4,6,8,10,12,13,16,17,23,25,27) \text { dan }(1, \\
2,5,7,9,11,14,15,18,19,20,21,22,24,26)\end{array}$ \\
\hline & & $\begin{array}{l}\text { tilu } \\
\text { telu }\end{array}$ & $\begin{array}{l}(3,4,6,8,10,12,13,16,17,23,25,27) \text { dan }(1, \\
2,5,7,9,11,14,15,18,19,20,21,22,24,26)\end{array}$ \\
\hline
\end{tabular}


HUMANIKA Vol. 23 No. 2 (2016) ISSN 1412-9418

Deskripsi Perbedaan Fonologi Bahasa -Bahasa Di Wilayah Barat Provinsi Jawa Tengah

Siti Junawaroh

\begin{tabular}{|l|l|l|l|}
\hline & & hitut & $(3,4,6,8,10,12,13,16,17,23,25,27)$ dan $(1$, \\
& & ngentut & $(3,7,9,11,14,15,18,19,20,21,22,24,26)$ \\
\hline $\mathrm{g}$ & $\varnothing-\mathrm{K} / \#-$ & utah & $2,5,7,9,11,14,15,18,19,20,21,22,24,26)$ \\
\hline & & mutah & $(3,4,6,8,10,12,13,16,17,23,25,27)$ dan $(1$, \\
& & aron & $2,5,7,9,11,14,15,18,19,20,21,22,24,26)$ \\
\hline & & karon & $(3,4,6,8,10,12,13,16,17,23,25,27)$ dan $(1$, \\
& & amis & $2,5,7,9,11,14,15,18,19,20,21,22,24,26)$ \\
\hline & & $(3,4,6,8,10,12,13,16,17,23,25,27)$ dan $(1$, \\
& & manis & $2,5,7,9,11,14,15,18,19,20,21,22,24,26)$ \\
\hline $\mathrm{h}$ & $\mathrm{R}(\mathrm{KV}) / \#-$ & jipis & $3,4,6,8,10,12,13,16,17,23,25,27)$ dan $(1$, \\
& & jantung & $(1,2,5,7,9,11,14,15)$ dan $(18,19,20,21,22,23$, \\
\hline & & jajantung & $24,26,27)$ \\
& & gusi & \\
\hline
\end{tabular}

\subsection{Variasi}

Variasi terjadi jika kaidah perubahan bunyi itu hanya terjadi pada sebuah atau dua buah contoh dengan sebaran geografis yang berbeda.Variasi digolongkan dalam dua kelompok, yakni variasi konsonan dan variasi vokal.

\subsubsection{Variasi konsonan}

Variasi konsonan terjadi ketika kosakata di suatu titik berbeda satu konsonan dengan kosakata pada titik pengamatan yang lain. Variasi konsonan yang terjadi pada posisi awal kata terjadi pada variasi d-n, h-k, h-ng, h-s, g-k, w-c dan K- Ø. Selain itu, ditemukan variasi konsonan yang terjadi pada posisi akhir kata, yakni $\mathrm{K}$ $\varnothing$. Berikut data untuk variasi konsonan.

\begin{tabular}{|c|c|c|c|}
\hline \multirow[t]{10}{*}{ No } & $\begin{array}{l}\text { Bentuk } \\
\text { realisasi }\end{array}$ & kosakata & Daerah pengamatan \\
\hline & d-n/\#- & $\begin{array}{l}\text { Danas } \\
\text { nanas }\end{array}$ & $\begin{array}{l}(3,4,6,8,10,12,13,16,17,23,25,27) \text { dan }(1, \\
2,5,7,9,11,14,15,18,19,20,21,22,24,26)\end{array}$ \\
\hline & h-k/\#- & $\begin{array}{l}\text { Hewan } \\
\text { kewan }\end{array}$ & $\begin{array}{l}5,8 \\
7,9\end{array}$ \\
\hline & h-ng/\#- & $\begin{array}{l}\text { Hitut } \\
\text { ngentut }\end{array}$ & $\begin{array}{l}(3,4,6,8,10,12,13,16,17,23,25,27) \text { dan }(1, \\
2,5,7,9,11,14,15,18,19,20,21,22,24,26)\end{array}$ \\
\hline & h-s/\#- & $\begin{array}{l}\text { Hiji } \\
\text { siji }\end{array}$ & $\begin{array}{l}(3,4,6,8,10,12,13,16,17,23,25,27) \text { dan }(1, \\
2,5,7,9,11,14,15,18,19,20,21,22,24,26)\end{array}$ \\
\hline & g-k/\#- & $\begin{array}{l}\text { gendeng } \\
\text { kenteng }\end{array}$ & $\begin{array}{l}1,2,5,7,9,11 \\
3\end{array}$ \\
\hline & & $\begin{array}{l}\text { Gosokan } \\
\text { kosokan }\end{array}$ & $\begin{array}{l}(3,4,6,8,10,12,13,16,17,23,25,27) \text { dan }(1, \\
2,5,7,9,11,14,15,18,19,20,21,22,24,26)\end{array}$ \\
\hline & W-c/\#- & $\begin{array}{l}\text { wringin } \\
\text { caringin }\end{array}$ & $\begin{array}{l}(3,4,6,8,10,12,13,16,17,23,25,27) \text { dan }(1, \\
2,5,7,9,11,14,15,18,19,20,21,22,24,26)\end{array}$ \\
\hline & V-vk & $\begin{array}{l}\text { Cakcak } \\
\text { cecak }\end{array}$ & $\begin{array}{l}(3,4,6,8,10,12,13,16,17,23,25,27) \text { dan }(1, \\
2,5,7,9,11,14,15,18,19,20,21,22,24,26)\end{array}$ \\
\hline & $\mathrm{M}(\mathrm{V})$ & $\begin{array}{l}\text { Gulet } \\
\text { gelut }\end{array}$ & $\begin{array}{l}1,2,5,7 \\
9,11\end{array}$ \\
\hline
\end{tabular}


HUMANIKA Vol. 23 No. 2 (2016) ISSN 1412-9418

Deskripsi Perbedaan Fonologi Bahasa -Bahasa Di Wilayah Barat Provinsi Jawa Tengah Siti Junawaroh

\begin{tabular}{|l|l|l|l|}
\hline & (an)/-\# & Langit-langit & $2,5,7$ \\
& & $1,9,11$ \\
\hline & & Uangitan & $1,5,9,11$ \\
& & Ugel-ugel & 2 \\
\hline & K- Ø/\#- & Ciduh & $(3,4,6,8,10,12,13,16,17,23,25,27)$ dan $(1$, \\
& Iduh & $2,5,7,9,11,14,15,18,19,20,21,22,24,26)$ \\
\hline & K- Ø/\#- & Wungu & 10 \\
& Kungu & 8 \\
& Ungu & $1,2,5,7,9,11$ \\
\hline & h- $\varnothing /-\#$ & ciduh & $(3,4,6,8,10,12,13,16,17,23,25,27)$ dan $(1$, \\
& idu & $2,5,7,9,11,14,15,18,19,20,21,22,24,26)$ \\
\hline
\end{tabular}

4.3.2. Variasi vokal

Variasi vokal terjadi ketika kosakata di suatu titik berbeda satu vokal dengan kosakata pada titik pengamatan yang lain. Variasi vokal yang terjadi pada posisi awal kata terjadi pada variasi i-u, di tengah i-e, uo, u-a, VV-V.Selain itu, ditemukan variasi vokal yang terjadi pada posisi akhir kata, yakni $\mathrm{V}-\varnothing$. Berikut data untuk variasi vokal.

\begin{tabular}{|l|l|l|l|}
\hline No & $\begin{array}{l}\text { Bentuk } \\
\text { realisasi }\end{array}$ & kosakata & Daerah pengamatan \\
\hline & i-e/(V) & $\begin{array}{l}\text { Gigir } \\
\text { Geger }\end{array}$ & $(3,4,6,8,10,12,13,16,17,23,25,27)$ dan $(1$, \\
$2,5,7,9,11,14,15,18,19,20,21,22,24,26)$
\end{tabular}


HUMANIKA Vol. 23 No. 2 (2016) ISSN 1412-9418

\section{SIMPULAN}

Perbedaan fonologi bahasa Jawa dan Sunda di wilayah barat Provinsi Jawa Tengah yang ditemukan meliputi korespondensi sangat sempurna, korespondensi kurang sempurna, dan variasi. Korespondensi sangat sempurna berupa korespondensi bunyi b-w. Korespondensi kurang sempurna berupa korespondensi h- $\varnothing$, Selain itu, terdapat pula variasi konsonand-n, h-k, h-ng, h-s, g$\mathrm{k}, \mathrm{w}-\mathrm{c}, \mathrm{K}-\varnothing$ dan variasi vokal i-u, i-e, u-o, u-a, VV-V, V- $\varnothing$. Perbedaan fonologi yang terdapat di wilayah barat Provinsi Jawa Tengah terjadi baik pada dua bahasa yang berbeda maupun dalam bahasa yang sama.

\section{DAFTAR PUSTAKA}

Hadiamaja, Sarjana.1982. Geografi Dialek Bahasa Jawa Kabupaten Cilacap. Yogyakarta: Pusat Pembinaan dan Pengembangan Bahasa.

Junawaroh, Siti.2010. "Kekerabatan dan Pemetaan Bahasa-Bahasa Di Kabupaten Brebes". Penelitian Riset Unggulan Daerah Kabupaten Brebes.

2009. "Pengaruh Bahasa Jawa terhadap Leksikon Bahasa Sunda di Kabupaten Brebes". Penelitian DIPA Universitas Jenderal Soedirman Purwokerto.

Junawaroh, Siti dan Ashari Hidayat. 2013.Leksikon Bahasa Jawa dalam Bahasa Sunda di Kabupaten Brebes. Adabiyat, Jurnal Bahasa dan Sastra. Jurusan Bahasa dan Sastra Arab, Fakultas Adab dan Ilmu Budaya UIN Sunan Kalijaga Yogyakarta.

Keraf, Gorys. 1984. Linguistik Bandingan Historis. Jakarta: PT Gramedia.

Lauder, Multamia R.M.T. 2002. "Reevaluasi Konsep Pemilih Bahasa dan Dialek untuk Bahasa Nusantara". Makara Sosial Humaniora, Vol.6 No.1, Juni 2002.
Lauder, Multamia R.M.T. 2005. Metodologi Penelitian Bahasa. Jakarta: Rajagrafindo Persada.

Mahsun. 1995. Dialektologi Diakronis: Sebuah Pengantar. Yogyakarta: UGM Press.

Nadra dan Reniwati. 2009. Dialektologi; Teori dan Metode. Yogyakarta: Elmatera Publishing.

Nothofer, Bernd.

1977.

Dialektgeographische

Untersuchung des Sundanesischen und des Entlang der Sundanesischen Sprachgrinze Gesprochenen Javanischen und Jakarta-Malaiischen. Ersten Teil. Köln: Philosophischen Fakultat der Universitảt zu Köln

Nothofer, Bernd. 1980. The Recontruction of Proto-Malayo-Javanic. SGravenhage-Martius Nijhoff.

Nothofer, Bernd. 1981. Dialektatlas von Zentral-Java. Wiesbaden: Otto Harrassowitz

Nothofer, Bernd. 1987."Cita-Cita Penelitian Dialek". Dewan Bahasa. 31:2. 
HUMANIKA Vol. 23 No. 2 (2016) ISSN 1412-9418

Deskripsi Perbedaan Fonologi Bahasa -Bahasa Di Wilayah Barat Provinsi Jawa Tengah Siti Junawaroh

Sudaryanto. 1988. Metode Linguistik Bagian Kedua; Metode dan Aneka Teknik Pengumpulan Data. Yogyakarta: Gadjah Mada University Press.

Suriamiharja, Agus. 1983. Geografi Dialek Sunda di Kabupaten Bogor. Jakarta: Jakarta: Pusat Pembinaan dan Pengembangan Bahasa.
Voegelin, C.F. dan Z.S, Harris. 1951. "Method for Determining Intelligibility among Dialects of Natural Language. Dalam Anthropological Philosopical Society-Proceeding. 